\title{
Editorial
}

\section{Embodied subjects in late capitalism}

Subjectivity (2016) 9, 145-150. doi:10.1057/sub.2016.6;

published online 7 April 2016

The contributors to this special section explore some of the ways in which our experience, understanding and imagining of the human body have changed in late capitalism. They help readers grasp the significant degree to which the global economy impacts daily embodied living. Together they demonstrate how global capitalism has enabled specific developments in the areas of medical and military technology, modes of governance, and ways of including the body in the 'global imaginary', as well as the global market.

The contributors problematize our understanding of the body as a distinct unit, separate from culture, politics, economics and from other bodies, and they all call attention to different modes of embodied-being-in-the-world, as understood within the context of Bauman (2000) and Giddens' (1991) observation that late capitalism transforms time and space. As time is compressed into a chronoscopic time of electronic instantaneity, and the prevailing social space becomes a virtual space in which borders, distances and regulations have less relevance, so too the human body undergoes similar, radical transformations. Today's liquid modernity, to use Bauman's concept, has developed into a visceral machinery capable of merging with bodies, leading to their reimagining as complex assemblages of various parts that can be dislocated, exchanged and replaced. In turn, this encourages individuals to be flexible and adaptable when it comes to their bodies; ready and willing to abandon commitments and loyalties to old ideas and beliefs, such as the body's integrity as sacred; to regard their own body parts as resources to be sold under difficult circumstances; to become 'militarized bodies' consisting of human-machine assemblages; or racialized bodies produced through what contributor Sam Binkley calls White anti-racism.

Specifically, the contributors engage with bodies portrayed in cinema as an expression of societal phantasy formations. These phantasy formations constitute part of a changing global imaginary and they are not just the representation of experience but they impact the represented, as they simultaneously express and shape experience. Phantasy scenarios speak of and construct the social imaginary through which one further understands and connects to bodies. The following essays, then, examine advances in 
medicine and military technology that blur the boundaries between separated bodies, as well as between bodies and machines. Each article incorporates concrete examples of particular experiences of embodiment, such as 'hybrid bodies' following an organ transplant, militarized bodies and racialized bodies (subjugated by the white gaze).

\section{Understanding Embodiment in Late Capitalism}

In exploring embodiment, I invite the reader to consider the body as formed and existing simultaneously in three different registers: the symbolic body, the imaginary (or ideal) body and the real body. The imaginary body could be conceptualized as the internalization of an image of our body, presented to us either by mirrors or by social and cultural models and aesthetical standards (Zwart, 1998, p. 113). Our symbolic body correlates the various medical maps that organize the body in various systems, such as the digestive and the cardiovascular systems (ibid.). This scientific representation of the body generates a mechanical understanding, classifying what was most likely earlier in life experienced as scattered and chaotic. The third register, the Real, designates that which is impossible to symbolize. For Jacques Lacan explanation of the Real is always in terms of the impossible: the Real is that which is impossible to bear (Sarup, 1992, p. 104).

The real body also includes what we might call visceral or non-cognitive dimensions, exemplified by Sartre's (1992) notion of the 'flesh' (la chair), a phenomenon characterized as 'the pure contingency of presence' (p. 343). It is the experience of flesh that gives rise to nausea, or a reaction to an experience impossible to bear and difficult to articulate. This concept gains further depth in Merleau-Ponty's (1962) writings, who addresses 'flesh' as belonging neither exclusively to the subject nor to the world, instead as a primal element out of which both are born in mutual relation. The 'flesh' is a kind of circuit that traverses the subject, but of which the subject is not the origin (Leder, 1999, p. 201). Like the Imaginary and the Symbolic, the Visceral cannot be properly identified with the subject; it is instead a power that traverses the subject, granting life in ways never fully understood (ibid., p. 203). When included in global capitalism, the human body suffers changes in all three registers.

Although many separate but related processes cause these changes, for example, accelerated rhythms of life, innovations in medical and military technology and new forms of governing bodies, the ubiquity of commodification provides a crucial leverage point to illuminate the impact of global capitalism upon embodiment. Here it is important to keep in mind that commodities are special kinds of goods only found where capitalism has penetrated (Appadurai, 1986, pp. 6-7). As Marx (1967) observed, as soon as a previously uncommodified object (a human body or organ) is thrust forth as a commodity, it is changed 
into something transcendent and stands in relation to all other commodities (p. 71). The social relation of people exists no longer between themselves, but between the products with which they participate in exchange on the market (ibid., p. 72). This 'fetishism of commodities' (ibid., p. 73) masks the history of production through monetary or exchange value (ibid., p. 183). Turning to our subject, the human body or organ as a commodity masquerades as a living, independent object and elides the actual humans and relations out of which they emerge. Just as we are made to see only the movement of commodities, rendering invisible the human labor that produced it, we are not able to see the individual from which the human organ was extracted (Garden and Murphree, 2007, p. 218). Through commodification and hence commodity fetishism, what was intimately linked to one's being one's own body or organ in our case- no longer belongs to the individual, and instead confronts him/her as an alien, hostile and independent entity.

In the context of contemporary trends in body commodification, it becomes important to pay attention to the effects of the expansion of markets, and of market values, into spheres of life where they did not previously belong (Sandel, 2013 , p. 7). The writings of Sandel have theorized the market's corrosive tendency as the very act of putting a price on things that corrupts them. The market expresses and promotes specific attitudes toward the goods being exchanged (Sandel, 2013, p. 9). We are not here dealing solely with the invasion of markets in what used to be intimate spaces of human existence, but also with an intensification of the speed of space and time specific to the shift from Modernity to Post-Modernity or Liquid Modernity (Bauman, 2000). The quickening of time and space triggers an inverse sense of slowing down of the subject; subjects do not perceive the shift as an external speeding up but rather of themselves slackening, and tend to feel as if the causes for maladjustment to the new rhythm of life lie within them and not in the larger social conditions. The passage from solid to liquid modernity confronts individuals with a series of challenges such as social forms, institutions and ways of thinking that no longer have enough time to solidify and cannot serve as frames of reference for human actions. Under these conditions of endemic uncertainty, individuals must abandon commitments to old modes of thinking, such as the understanding of the body's sacred integrity, and come to view body parts as truly 'human resources' and potential commodities (Bauman, 2000, p. 21).

These radical changes have generated ruptures in the fabric of embodied reality. These are moments of interruption of the flow of social life, where the coordinates that organize existence, including one's experience and understanding of one's body and subjectivity, undergo a dramatic shift (Eisenstein and McGowan, 2012, pp. 3-4). In the essays below, these changes are triggered by the earlier discussed advances in medical and military technology coupled with the deeper and broader penetration of market principles, values and accelerated pace into areas of life that were prior considered intimately human. The newly generated reality has distinct principles and rhythm, and indeed clashes with and 
distorts the old social plane, causing traumatic ruptures. Such ruptures are illustrated in this special section by the open, fragmented or hybrid body, as well as by bodies viscerally integrated into military assemblages.

\section{Special Section's Articles}

Hub Zwart in his article explores the way embodiment and human subjectivity are affected by innovations in transplant medicine. He examines these transformations from a Lacanian perspective while using cinema as his main field of analysis. Three organ transplantation films are engaged, namely Jésus de Montréal (1989), L'Intrus (2004) and Crank 2: high voltage (2009). Zwart argues that movies are highly relevant in understanding aspects of radical social change, as they relate to contemporary culture in a way that is similar to how dreams relate to everyday consciousness. Specifically they provide a stage where our understanding of embodiment can be enacted, probed and questioned. Zwart also stresses that, because of changes in biomedicine, the human body ceases to be envisioned as an indivisible unity but has instead become an aggregate of replaceable parts. It is the author's main claim that these changes represent an ontological trauma or a rupture of the fabric of reality, entailing an ontological revelation and an opening up of the human body to fragmentation. Organs and other body parts may be removed and replaced by partial objects of desire, procurable from others. Yet even if the new organ or part appears to function well, it remains tainted by otherness, both biologically and figuratively. It remains something utterly beyond our grasp as individuals, while unleashing the desire of 'craving subjects'. Zwart claims that transplant medicine reveals the extent to which fragmentation and alienation constitute a profound and primordial dimension of embodiment as such.

Sam Binkley considers the problem of race as an effect of the process of knowing and governing, with the aim of unmasking hidden continuities between racism and anti-racism. In advanced capitalist societies, Binkley argues, antiracism is an institutional formation that targets the behaviors and dispositions of the dominant racial group, seeking to convert chauvinistic assumptions by inducing a sensitivity and tolerance to cultural diversity (associated with expressions such as 'multi-culturalism', 'diversity' and 'inclusion'). Binkley argues that anti-racism invokes a certain technology of knowing whose function is to authorize empathic understanding while attributing profound and irreducible differences to racialized individuals and populations. In this way, the apparatus of White anti-racism reproduces many of the key categories, assumptions and relations of racism that it tries to eradicate. Binkley proposes an alternative antiracism by exposing the limits of existing ones. The point is to consider the limitations of the anti-racism juridical frame and to expand the range of possible 
anti-racist practices beyond the need to pay a debt that, in the author's opinion, must never be fully paid. This is the case, in part because the payment reminds us of a certain economy of obligations that is meant to reverse the effects of an older contract premised on racial inequality. Instead Binkley envisions a formation of the self, or an opening of a new relation to the self as one of possibility and innovation. He refers to it as an 'askesis', or an art of the self, understood as an ethical practice, a way of making or remaking the self, holding the potential to transform the way we think about moral and political problems in the present. It points the way to a White anti-racism of self-fashioning from within.

Florentina C. Andreescu investigates how the contemporary war dispositif in cinematic representations captures and integrates bodies, gestures, space and desire. She explores the cinema dispositif in close connection to the military one. In this sense she follows the tradition, set by cultural and media theorists such as Virilio (1989) and Kittler (1999), that highlights a genealogy of media in which war functions as generator of all technical things. Andreescu's article focuses on two analytic concepts, suture and interpassivity, and shows how soldiers, in cinematic space, confront trauma that results from an incompatibility between the accelerated speed of military dispositif and the slower rhythms of everyday life. She conceptualizes suture as the process through which the subject enters the militarized space and accepts it as part of reality. The subject/soldier assumes the weapon's point of view as her/his own. For this process to occur the weapon's perceptual effect must be conjured away, so that the soldier can operate under the illusion that what is seen has an autonomous existence (Sarup, 1992, p. 154). Furthermore, interpassivity refers to people's desire to enjoy not in the sense of actively having fun, but in the sense of enjoying the protection they get from the machine to which they have attached themselves. It perversely makes subjects enjoy their own unhappiness (van Oenen, 2010). The author argues that the military dispositif reshapes the social imaginary of the body, further altering one's experience of what it feels like to be an embodied being. The body, as it is experienced in everyday life, disappears and finds itself reduced to a machine-like entity, acquiring a different rhythm and being rewired in terms of capabilities of enjoyment. Andreescu analyzes the clash between life-speeds through three cinematic texts - The Hurt Locker (2008), American Sniper (2014) and Good Kill (2014) - and clarifies how such disruptions motivate attempts to manage and renegotiate realities fractured by traumatic war experiences. More generally, she analyzes the ways in which war disfigures the phenomenology of bodies and the life world.

\section{References}

Appadurai, A. (1986) The Social Life of Things: Commodities in Cultural Perspective. Cambridge, UK: Cambridge University Press. 
Arcand, D. (1989) Jésus de Montréal. Centre National de la Cinématographie (CNC).

Bauman, Z. (2000) Liquid Modernity. Cambridge: Polity.

Bigelow, K. et al. (2008) The Hurt Locker. Roadshow Home Entertainment, Australia.

Denis, C. (2004) L'Intrus. Ognon Pictures.

Eastwood, C. et al. (dir.) (2014) American Sniper. Warner Home Video (Firm).

Eisenstein, P. and McGowan, T. (2012) Rupture: On the Emergence of the Political. Evanston, IL: Northwestern University Press.

Garden, R. and Murphree, H.J.Y. (2007) Class and ethnicity in the global market for organs: The case of Korean cinema. Journal of Medical Humanities 28(4): 213-229.

Giddens, A. (1991) Modernity and Self-Identity: Self and Society in the Late Modern Age. Stanford, CA: Stanford University Press.

Kittler, F.A. (1999) Gramophone, Film, Typewriter. Stanford, CA: Stanford University Press.

Leder, D. (1999) Flesh and blood: The proposed supplement to Merleau-Ponty. In: D. Welton (ed.). The Body: Classic and Contemporary Readings. Oxford and Malden, MA: Wiley-Blackwell, pp. 200-210.

Marx, K. (1967) Capital: A Critique of Political Economy. New York: International Publishers.

Neveldine, M. and Taylor, B. (2009) Crank 2: High Voltage. Lionsgate.

Niccol, A. et al. (dir.) (2014) Good Kill. Paramount Pictures Corporation.

Sandel, M.J. (2013) What Money Can't Buy: The Moral Limits of Markets. New York: Farrar, Straus and Giroux.

Sartre, J.-P. (1992) Being and Nothingness: A Phenomenology Essay on Ontology. New York: Washington Square Press.

Sarup, M. (1992) Jacques Lacan. Toronto, Canada: University of Toronto Press.

Merleau-Ponty, M. (1962) Phenomenology of Perception [Phénoménologie de la Perception]. London: Routledge \& Kegan Paul.

van Oenen, G. (2010) Three cultural turns: How multiculturalism, interactivity and interpassivity affect citizenship. Citizenship Studies 14(3): 293-306.

Virilio, P. (1989) War and Cinema: The Logistics of Perception. New York: Verso Books.

Zwart, H. (1998) Medicine, symbolization and the 'real' body - Lacan's understanding of medical science. Medicine, Health Care and Philosophy 1(2): 107-117.

Florentina C. Andreescu International Studies, University of North Carolina Wilmington, Wilmington, NC, USA E-mail: andreescuf@uncw.edu 